\title{
Corrigendum
}

\section{Corrigendum to "Impact of Postmigration Living Difficulties on the Mental Health of Afghan Migrants Residing in Istanbul"}

\author{
Qais Alemi, ${ }^{1}$ Carl Stempel, ${ }^{2}$ Kelly Baek, ${ }^{1}$ Lisa Lares, ${ }^{1}$ \\ Patricia Villa, ${ }^{1}$ Didem Danis, ${ }^{3}$ and Susanne Montgomery ${ }^{4}$ \\ ${ }^{1}$ Department of Social Work and Social Ecology, School of Behavioral Health, Loma Linda University, Loma Linda, CA 92354, USA \\ ${ }^{2}$ Department of Sociology and Social Services, California State University, East Bay, Oakland, CA 94607, USA \\ ${ }^{3}$ Department of Sociology, Galatasaray University, 34349 Istanbul, Turkey \\ ${ }^{4}$ Department of Social Work \& Social Ecology, Behavioral Health Institute, Loma Linda University, Redlands, CA 92373, USA
}

Correspondence should be addressed to Qais Alemi; qalemi@llu.edu

Received 13 December 2016; Accepted 21 December 2016; Published 12 January 2017

Copyright (C) 2017 Qais Alemi et al. This is an open access article distributed under the Creative Commons Attribution License, which permits unrestricted use, distribution, and reproduction in any medium, provided the original work is properly cited.

In the article titled "Impact of Postmigration Living Difficulties on the Mental Health of Afghan Migrants Residing in Istanbul" [1], the first sentence in the Introduction should be corrected as follows.

"The volatile civil war in Syria and conflict and economic instability in Iraq, Afghanistan, and North Africa have led to unprecedented population movements to the European Union (EU)."

\section{References}

[1] Q. Alemi, C. Stempel, K. Baek et al., "Impact of postmigration living difficulties on the mental health of Afghan migrants residing in Istanbul," International Journal of Population Research, vol. 2016, Article ID 7690697, 8 pages, 2016. 


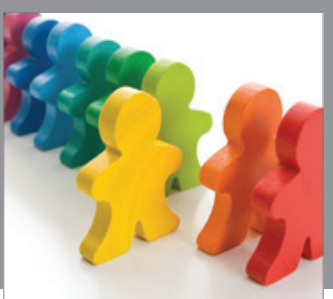

Autism

Research and Treatment
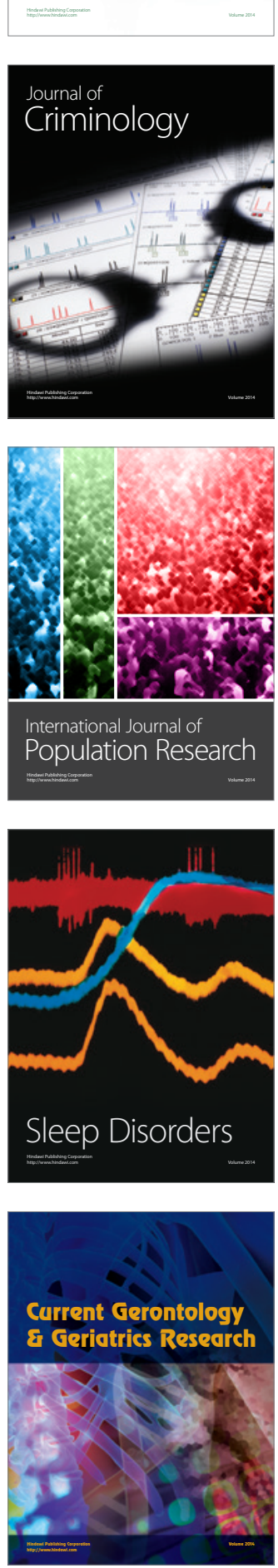

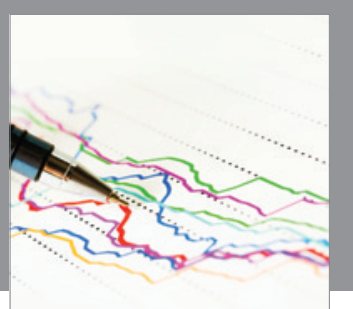

Economics

Research International
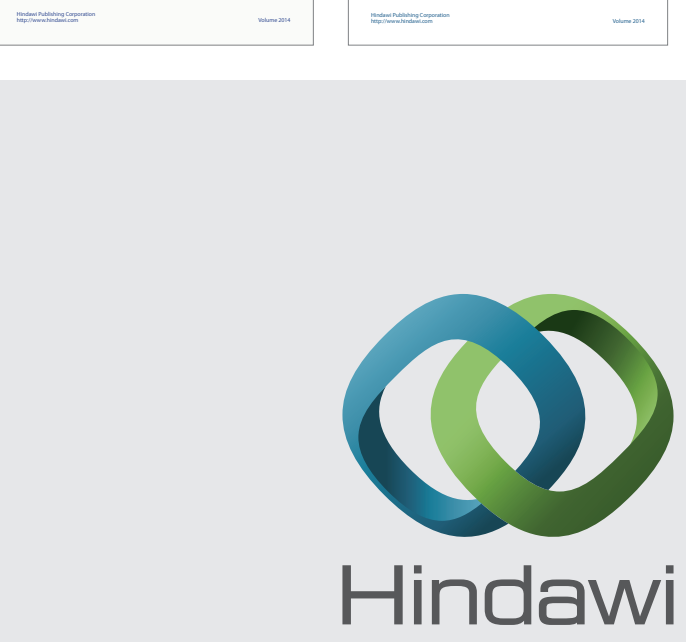

Submit your manuscripts at

https://www.hindawi.com
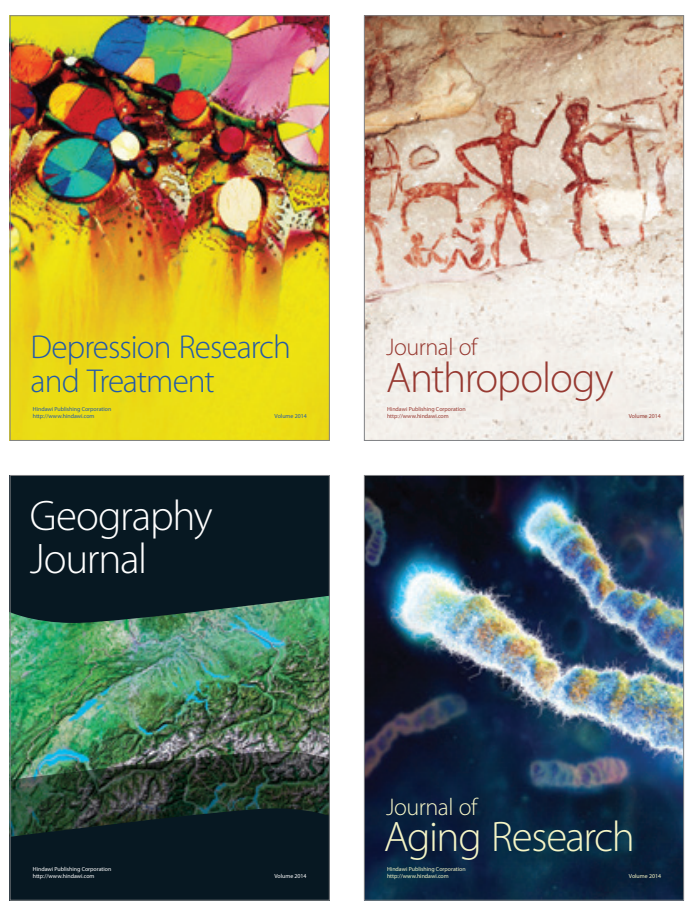
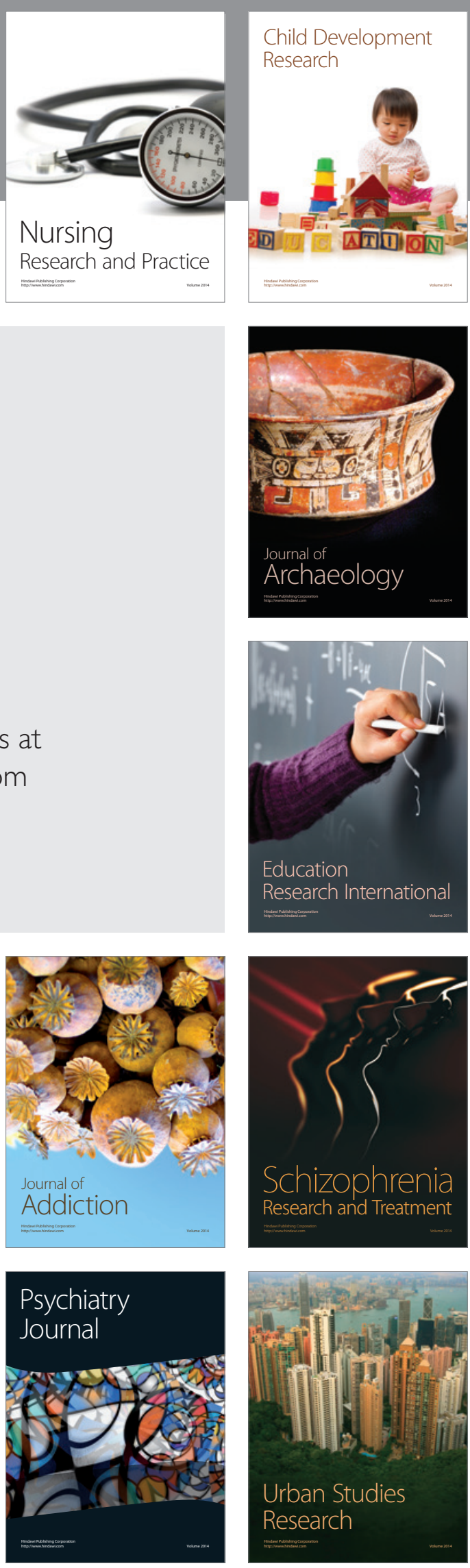